\title{
SUBCRITICAL WATER EXTRACTION OF GINGEROL FROM ZINGIBER OFFICINALE
}

\author{
M. E. Yulianto ${ }^{1}$, P. Kusumo ${ }^{2}$, I. Hartati ${ }^{3 *}$ and Wahyuningsih ${ }^{1}$ \\ ${ }^{1}$ Diploma III Programme of Chemical Engineering, Diponegoro University, Indonesia \\ ${ }^{2}$ Chemical Engineering Department, Semarang 17 August University, Indonesia \\ ${ }^{3}$ Chemical Engineering Department, Wahid Hasyim University, Indonesia \\ *E-mail:hartatiprasetyo@gmail.com
}

\begin{abstract}
Zingiber officinale contains various active components. One of the active compounds that exhibit many pharmacological effects is gingerol. Considering the health benefits offered by active compounds of Zingiber officinale, recently many researchers are searching and investigating the right choice of the extraction and separation techniques. Hydrothermal extraction is a new promising technique that gaining many interests from researchers over its numerous benefits. The investigation of subcritical water extraction of gingerol as one of the active constituent of Zingiber officinale was the objective of this research. Experiments were carried out at a temperature of $130-140^{\circ} \mathrm{C}$, at a fixed pressure of 2 bar, and samples were taken every 10 minutes to be further analyzed. The research showed that gingerol content of the extract was up to $5 \%$ obtained from subcritical water extraction carried out at a temperature of 130 minutes, the pressure of 3 bar and extraction time of 20 minutes.
\end{abstract}

Keywords: zingiber officinale, gingerol, subcritical water, extraction

(c) RASĀYAN. All rights reserved

\section{INTRODUCTION}

Zingiber officinale Roscoe, commonly known as ginger, is a monocotyledon belonging to family Zingiberaceae. Ginger is a slender perennial plant that reaches the height of 2 feet. Ginger has greenish yellow flowers resembling orchids. Ginger is thought to be originally native to tropical South East Asia and then became widespread in many ecological zones. ${ }^{1,2}$ Ginger is a common herb used in food as a spice and also used as herbal medicines. Ginger is known for its unique and significant therapeutic effects such as anticancer, antioxidant, anticoagulant, cardiovascular effect, antimicrobial, antiemetic, antipyretic, anti-inflammatory and chemoprotective potential. ${ }^{3,4}$ The pharmacological activities of ginger is due to the presence of numerous active compounds. Gingerol, paradol and shogaol are reported as the components that are responsible for the ginger pharmacological activities. ${ }^{4-7}$

Many researchers stated that gingerol, the phenolic substance has been found to possess many interesting and diverse physiological and pharmacological activities. These are including analgesic, antitussive, cardiotonic, gastroprotective, anti-inflammatory, anti-oxidant, anti-pyretic, anti-hepatotoxic, antiangiogenic, anti-hyperglycemic, anti-tumor, anti-cancer and anti-platelet aggregation activities, and hypotensive effects. ${ }^{3,4,8-13}$

Considering the health benefits offered by the active constituent of Zingiber officinale rhizome, the finding of an appropriate separation technique is an urge. Nowadays, the application of subcritical water as the medium of extraction has gained much interest from researchers. Subcritical water is considered as water at temperatures between 100 and $374^{\circ} \mathrm{C}$ that are maintained in a liquid state by controlled its pressure. In the subcritical region, water has several unique properties that are namely its disproportionately high boiling point for its mass, a high dielectric constant and high polarity. ${ }^{10,14,15}$ As the temperatures rise in the subcritical water region, the permittivity of the water, the viscosity and the surface tension significantly decrease, while the diffusion rate increases. ${ }^{14}$ In consequence, more polar target materials with high solubility in water at ambient conditions are extracted most efficiently at lower 
temperatures, whereas elevated temperature will induce the moderately polar and non-polar targets which require a less polar medium. ${ }^{10,15,16}$

Considering the numerous pharmacological effect offered by ginger active constituent namely gingerol and the advantages of the application of subcritical water in the phytoconstituents separation, thus in this paper, we investigated the influence of the parameter process on the subcritical water extraction of gingerol.

\section{Material and Methods}

\section{EXPERIMENTAL}

Dried and ground ginger was supplied by a local supplier from Semarang, Central Java, Indonesia. Distilled water was used in the subcritical water extraction. The subcritical water extractor used in this research was shown in Fig.-1. Two vessels having a volume of five-liter volume each are connected with a stainless steel pipe. The first vessel acts as the extractor column while the other one is acting as the cooling cells.

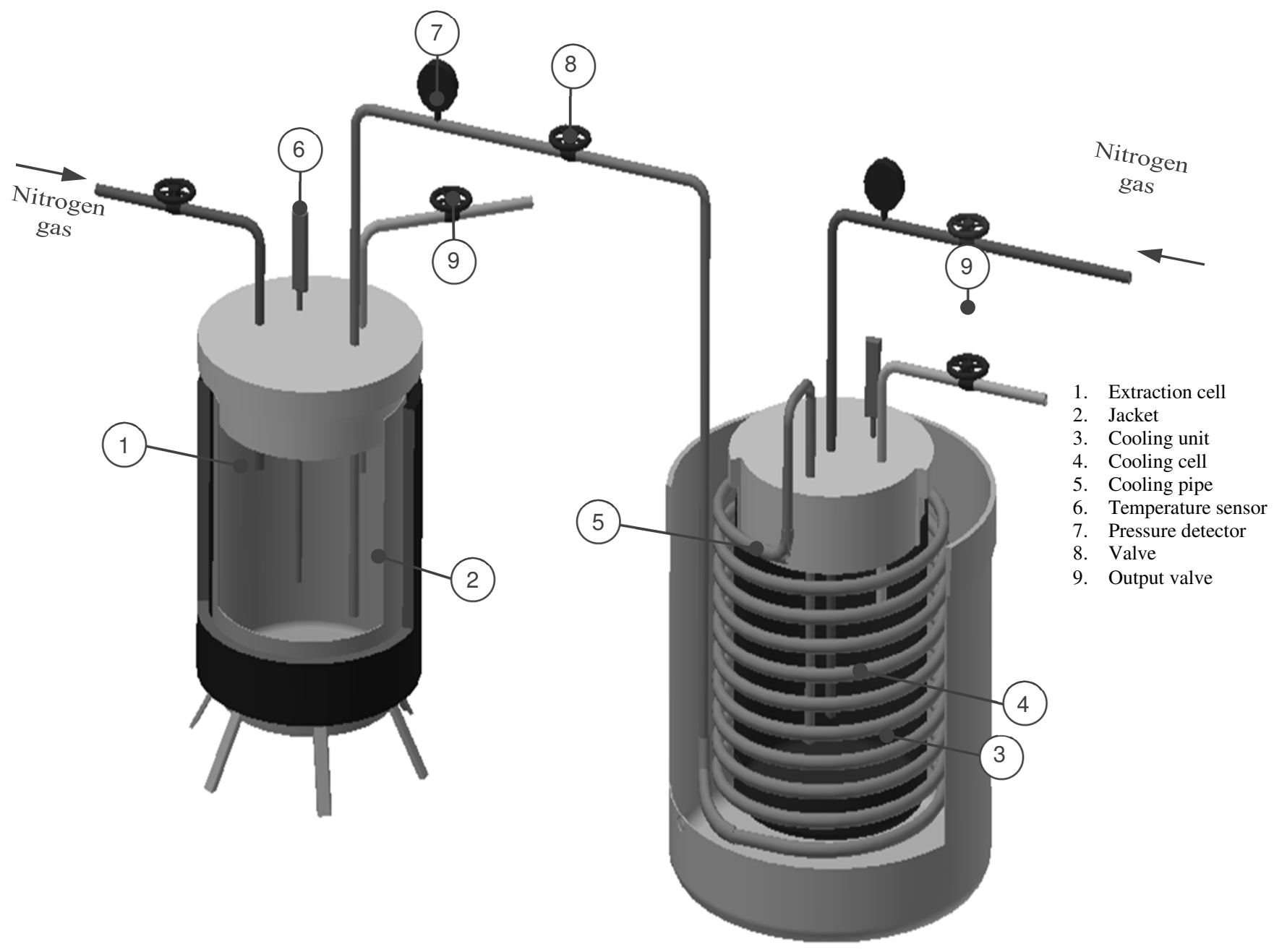

\section{General procedure}

Fig.-1: Subcritical water reactor

$100 \mathrm{~g}$ of ground ginger added to the extractor cell. A certain volume of distilled water $(4000 \mathrm{ml})$ was then added into the cell. After the stainless steel lid cover was securely covered the column, the $\mathrm{N}_{2}$ gas was then passed through the cell for 2 min to purge out air. The $\mathrm{N}_{2}$ gas was also used to maintain the pressure of the chamber fixed at 2 bar. The extraction was conducted at a temperature of $130-140^{\circ} \mathrm{C}$ for $10-20$ 
RASĀYAN J. Chem.

Vol. 10 | No. 3 |738 - 743 | July - September | 2017

minutes. Once the extraction process was completed, the extract was transferred into the cooling cell at 25 ${ }^{0} \mathrm{C}$ and $1 \mathrm{MPa}$ within $1 \mathrm{~min}$ to ensure rapid cooling.

\section{Analytical Discussion}

The samples were taken and subjected to HPLC-MS analysis. The LC-MS used was a UPLC- QToFMS/MS System (Waters). The column of the LC-MS was Acquity UPLC BEH C18 1.7um, 2.1x50 mm. The eluent were: (A) $\mathrm{H} 2 \mathrm{O}+0.1 \%$ formic acid, and (B): Acetonitrile $+0.1 \%$ formic acid. The flow rate was $0.3 \mathrm{~mL} / \mathrm{min}$ injected at $40 \mathrm{dC}$ and volume of $5 \mathrm{uL}$. The MS used was XEVO - G2QTOF (Waters) with ESI positive in resolution mode. The data were analyzed by using MassLynk version 4.1.software.

\section{RESULTS AND DISCUSSION}

Ginger is reported contains a numerous number of pungent constituents and active ingredients. It was mentioned that the ginger chemical constituents are vary depending on the place of origin and whether the rhizomes are fresh or dry. ${ }^{4,7}$ Studies recorded by Jolad has identified 63 compounds in fresh ginger. ${ }^{17}$ Meanwhile, the chemical constituents on commercially processed dry ginger were also examined. ${ }^{7}$ They found a total of 115 compounds, of which 88 were reported. Of these, 45 had been recorded previously for fresh ginger. ${ }^{717}$ Basically, the ginger compounds are grouped into two broader categories i.e., volatiles and non-volatiles. Both of the ginger compounds group are contributing to specific pungency in different ways. The volatiles determines the odor of ginger, and the yield of which varies from $1 \%$ to $3 \%$. ${ }^{7,18}$ The volatiles include sesquiterpene and monoterpenoid hydrocarbons providing the distinct aroma and taste of ginger. The monoterpenoid hydrocarbons are included geraniol, curcumene b-phellandrene, (+)camphene, 1,8-cineole, citral, terpineol, borneol, linalool, and neral, while the sesquiterpenes are included zerumbone, a-zingiberene, b-sesquiphellandrene, b-bisabolene, (E-E)-a-farnesene, arcurcumene, and zingiberol. On the contrary, non-volatile pungent compounds include gingerols, shogaols, paradols, and zingerone. ${ }^{2,7}$

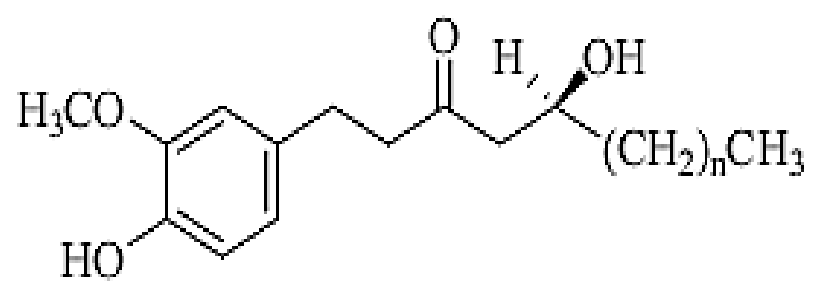

Fig.-2: Basic Chemical Structure of Gingerol

Gingerols (Fig.-2) are mainly attributed for ginger-specific pungency. Gingerols are homologous series of phenols. They differ in their unbranched alkyl chains length ${ }^{2}$. Gingerol is formed in the plant from malonate, phenylalanine, and hexonate. ${ }^{19}$ 6-gingerol [5-hydroxy-1-(4-hydroxy-3-methoxy phenyl) decan3 -one is the most abundant constituent among the gingerol series. ${ }^{8}$

Phytochemical constituents are usually thermally unstable. Gingerols also reported having the characteristic of thermally unstable and can undergo at least two reactions. ${ }^{20}$ Several attempts on the gingerol separation were investigated in order to optimize the separation process and minimize the gingerol thermal degradation. Subcritical water was used in the gingerol extraction. The temperature of the system was set of 130 and $140^{\circ} \mathrm{C}$, the extraction duration was varied between 10-40 minutes, while the pressure was set at 2 bar by using $\mathrm{N}_{2}$. The profile of the LC-MS chromatogram of gingerol in subcritical water extraction was shown on Figures- 3 to 5.

The research result showed that the gingerol content of the extract was high. The gingerol content of the extract was found of $5 \%$ at the subcritical water extraction performed at a temperature of $130^{\circ} \mathrm{C}$, the pressure of 2 bar and extraction time of 20 minutes. While the gingerol content of the extract was found of $4 \%$ at the subcritical water extraction performed at a temperature of $130^{\circ} \mathrm{C}$ and $140^{\circ} \mathrm{C}$, the pressure of 2 
bar and extraction time of 20 minutes. This result was higher than the gingerol content found on the thermally processed ginger that was reported in the earlier studies conducted by Purnomo. ${ }^{21}$

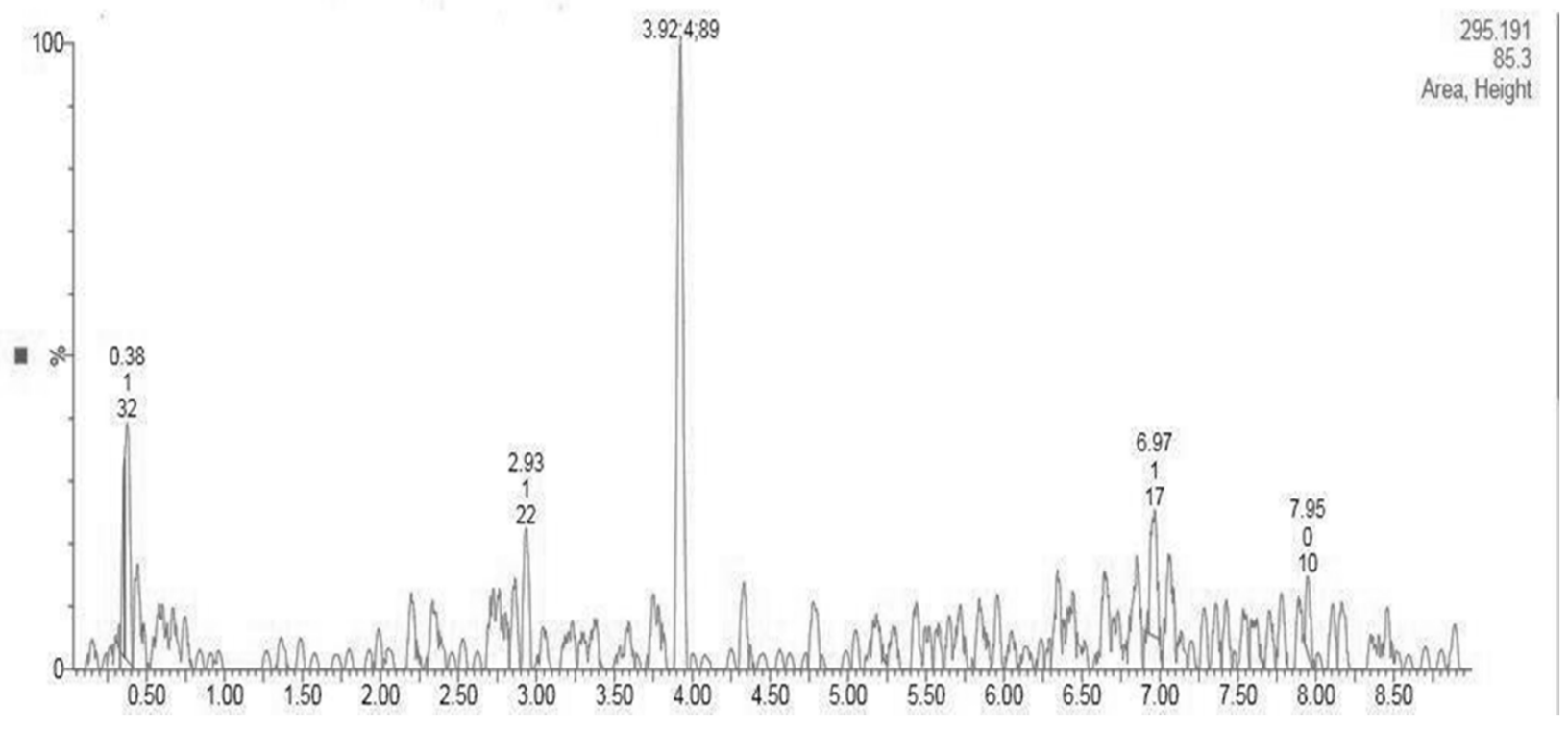

Fig.-3: LC-MS chromatogram of gingerol in subcritical water extraction performed at temperature of $130^{\circ} \mathrm{C}$, pressure of 2 bar and extraction time of 10 minutes

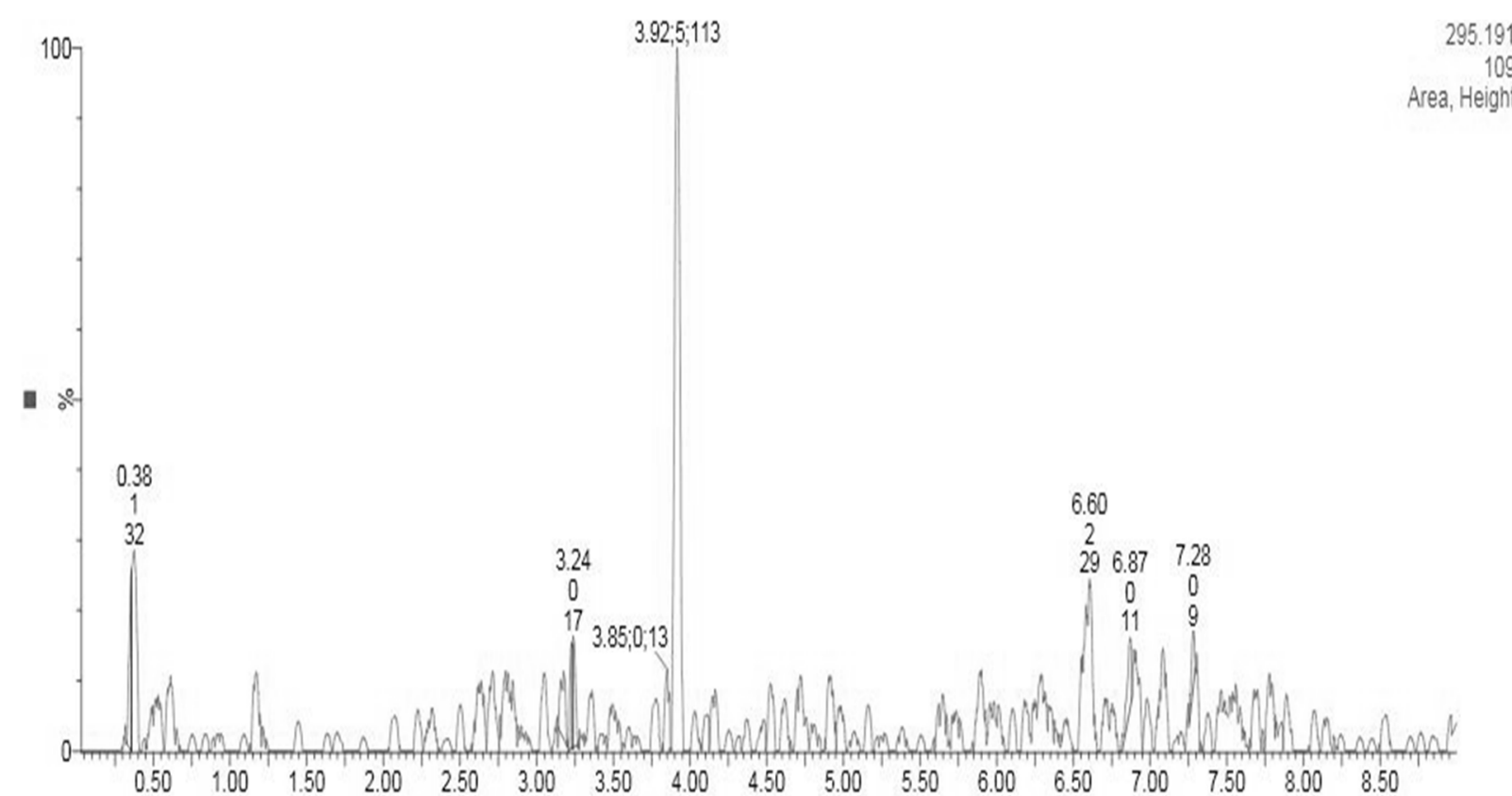

Fig.-4: LC-MS chromatogram of gingerol in subcritical water extraction performed at temperature of $130^{\circ} \mathrm{C}$, pressure of 2 bar and extraction time of 20 minutes

They conducted roasting on the elephant ginger and applied two different thermal processing, i.e. boiling at $100^{\circ} \mathrm{C}$ and roasting at $320^{\circ} \mathrm{C}$ for $2-10$ minutes. They found that the gingerol content were up to $0,78-2 \%$ and $0,8 \%-1,9 \%$, respectively. ${ }^{21}$ The different genetics, plantation techniques, varieties, and its 
environments were might be the cause of the different figures of the gingerol content. But, moreover, the most important things it might be due to the different thermal process applied on the ginger processing.

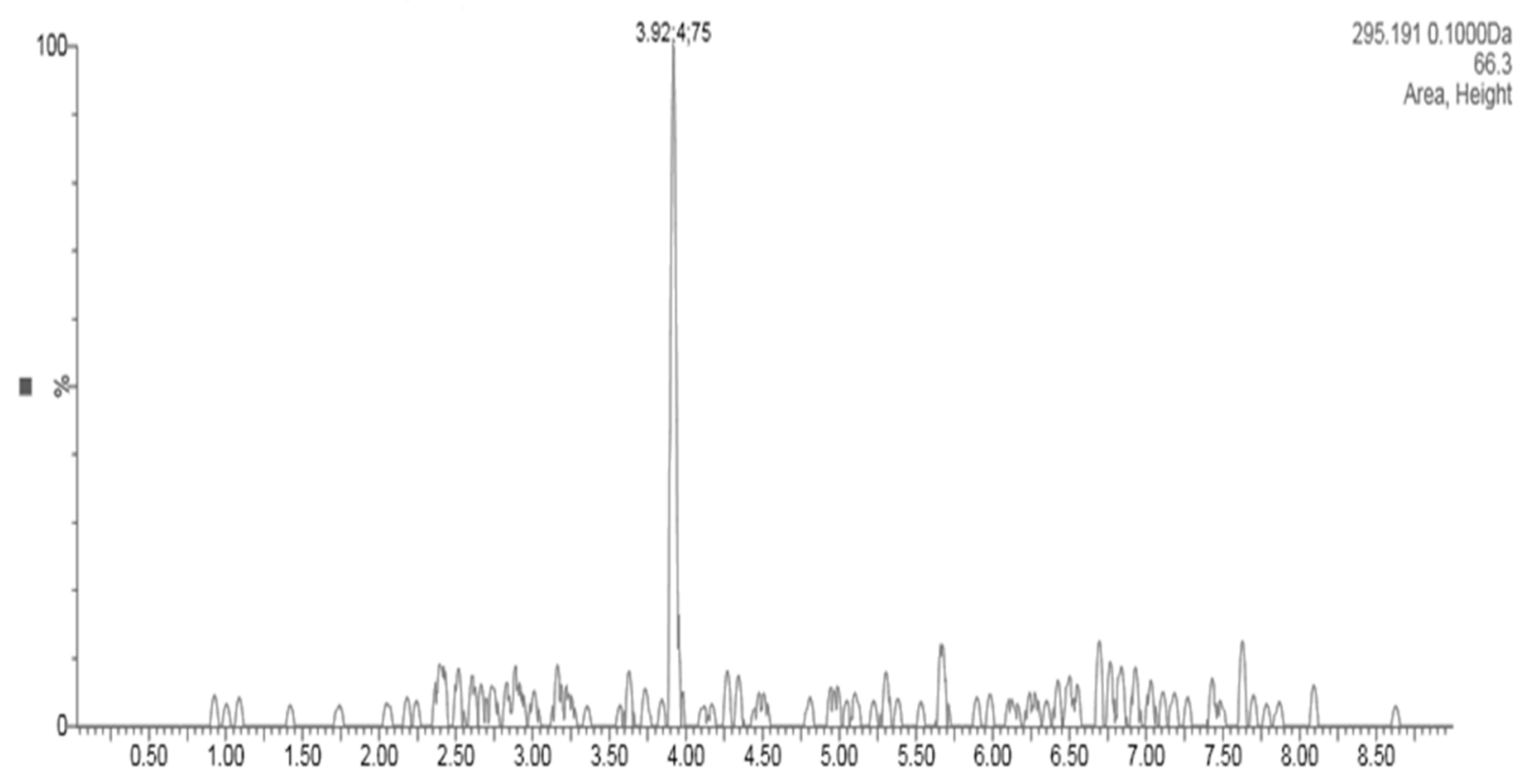

Fig.-5: LC-MS chromatogram of gingerol in subcritical water extraction performed at a temperature of $140^{\circ} \mathrm{C}$, the pressure of 2 bar and extraction time of 10 minutes.

The application of subcritical water as the extraction medium was proven to be better techniques. It might be due to the unique properties of water which are in the subcritical region such as the low of the water permittivity, the viscosity, and the surface tension, and also the high of the diffusion rate. Moreover, the most important advantages of subcritical water extraction over traditional extraction techniques applied in the phyto-constituents separation are lower costs of the extracting agent, shorter extraction time, and an environmentally compatible technique.

\section{CONCLUSION}

The application of subcritical water as the extraction medium in the gingerol separation from ginger rhizomes was proven to be better techniques and yield high gingerol content. The research showed that gingerol content of the extract was up to $5 \%$ obtained from subcritical water extraction carried out at a temperature of 130 minutes, the pressure of 3 bar and extraction time of 20 minutes.

\section{ACKNOWLEDGMENT}

We would like to thank the Agriculture Research and Development Agency, Ministry of Agriculture, Indonesia, through a partnership of national agricultural research and development (KKP3N) for the financial support of this research.

\section{REFERENCES}

1. C.A. Anosike, O. Obidoa, L.U.S. Ezeanyika, and M.M. Nwuba, African Journal of Biochemistry Research., 3 (12), 379 (2009).

2. M.S. Butt, and M.T. Sultan, Critical Reviews in Food Science and Nutrition., 51, 384 (2011).

3. E.J.V. Cafino, M.B. Lirazan, and E.C. Marfori, International Journal of Pharmacognosy and Phytochemical Research., 8 (1), 38 (2016). 
RASĀYAN J. Chem.

Vol. 10 | No. 3 |738 - 743 | July - September | 2017

4. R.K. Mishra, and A. Kumar, International Journal of Pharmaceutical and Chemical Sciences, 1 (3), 1422 (2012).

5. S. Malhotra, and A.P. Singh, Natural Product Radiance., 2 (6), 297 (2003).

6. S.K. Gupta, and S. Kumar, IOSR Journal of Pharmacy and Biological Sciences., 9, 69 (2014).

7. B.H. Ali, G. Blunden, M.O. Tanira, and A. Nenmar, Food and Chemical Toxicology., 46, 410, (2008).

8. S. Kumar, K. Saxena, U.N. Singh, and R. Saxena, International Journal of Herbal Medicine., 1(4), 16 (2013).

9. S. Mahluji, A. Ostadrahimi, M. Mobasseri, V.E. Attari, and L. Payahoo, Advanced Pharmaceutical Bulletin., 3(2), 273 (2013).

10. M.S. Sarip, N.A. Morad, N.A.M. Ali, Y.A.M. Yusof, M.A.C. Yunus, Separation and Purification Technology, 124, 141 (2014).

11. J. Guo, H. Wu, L. Du, W. Zhang, and J. Yang, Journal of Agriculture Science Technology., 16, 1063 (2014).

12. S. Prasad, and A.K. Tyagi, Gastroenterology Research and Practice, Article ID 142979, 2 (2015).

13. M.B. Hossain, N.P. Brunton, C. Barry-Ryan, A.B. Martin-Diana, and M. Wilkinson. Rasayan J. Chem., 1 (4), 751 (2008)

14. S.M. Ghoreishi, R.G. Shahrestani, and S.H. Ghaziaskar, World Academy of Science, Engineering and Technology, 43, 115 (2008).

15. A. Haghighi, and M. Khajenoori, Subcritical Water Extraction. Mass Transfer - Advances in Sustainable Energy and Environment Oriented Numerical Modeling, 459 (2013).

16. C.C. Teo, S.N.Tan, J.W.H. Yong, C.S. Hew, and E.S. Ong, Journal of Chromatography., 1217 (16), 2484 (2010).

17. S.D. Jolad, R.C. Lantz, A.M.Solyom, G.C. Chen, B. Bates, and B.N.Timmermann, Phytochemistry, 65, 1938, (2004).

18. R. Ramakrishnan, International Journal of Medicine and Pharmaceutical Sciences., 3, 11, (2013).

19. A.K. Ghosh, International Journal of Pharma and Bio Sciences., 2, 283, (2011).

20. H. Wohlmuth, Dissertation at Southern Cross University., 92 (2008).

21. H. Purnomo, F. Jaya, and S.B. Widjanarko, International Food Research Journal., 17, 335 (2010).

[RJC-1619/2017] 